\title{
Humidification Performance of Two High-Flow Nasal Cannula Devices: A Bench Study
}

\author{
Yusuke Chikata PhD, Masayo Izawa MD, Nao Okuda MD, Taiga Itagaki MD, \\ Emiko Nakataki MD, Mutsuo Onodera MD, Hideaki Imanaka MD, \\ and Masaji Nishimura MD
}

\begin{abstract}
INTRODUCTION: Delivering heated and humidified medical gas at $20-60 \mathrm{~L} / \mathrm{min}$, high-flow nasal cannula (HFNC) creates low levels of PEEP and ameliorates respiratory mechanics. It has become a common therapy for patients with respiratory failure. However, independent measurement of heat and humidity during HFNC and comparison of HFNC devices are lacking. METHODS: We evaluated 2 HFNC (Airvo 2 and Optiflow system) devices. Each HFNC was connected to simulated external nares using the manufacturer's standard circuit. The Airvo 2 outlet-chamber temperature was set at $37^{\circ} \mathrm{C}$. The Optiflow system incorporated an $\mathrm{O}_{2}$ /air blender and a heated humidifier, which was set at $40^{\circ} \mathrm{C} /-3$. For both systems, HFNC flow was tested at 20,40 , and $50 \mathrm{~L} / \mathrm{min}$. Simulating spontaneous breathing using a mechanical ventilator and TTL test lung, we tested tidal volumes $\left(V_{T}\right)$ of 300,500 , and $700 \mathrm{~mL}$, and breathing frequencies of 10 and 20 breaths $/ \mathrm{min}$. The TTL was connected to the simulated external nares with a standard ventilator circuit. To prevent condensation, the circuit was placed in an incubator maintained at $37^{\circ} \mathrm{C}$. Small, medium, and large nasal prongs were tested. Absolute humidity $(\mathrm{AH})$ of inspired gas was measured at the simulated external nares. RESULTS: At 20, 40, and $50 \mathrm{~L} / \mathrm{min}$ of flow, respective AH values for the Airvo 2 were $35.3 \pm 2.0,37.1 \pm 2.2$, and $37.6 \pm 2.1 \mathrm{mg} / \mathrm{L}$, and for the Optiflow system, $33.1 \pm 1.5,35.9 \pm 1.7$, and $36.2 \pm 1.8 \mathrm{mg} / \mathrm{L}$. AH was lower at $20 \mathrm{~L} / \mathrm{min}$ of HFNC flow than at 40 and $50 \mathrm{~L} / \mathrm{min}(P<.01)$. While AH remained constant at 40 and $50 \mathrm{~L} / \mathrm{min}$, at $20 \mathrm{~L} / \mathrm{min}$ of $\mathrm{HFNC}$ flow, $\mathrm{AH}$ decreased as $\mathrm{V}_{\mathrm{T}}$ increased for both devices. CONCLUSIONS: During bench use of HFNC, AH increased with increasing HFNC flow. When the inspiratory flow of spontaneous breathing exceeded the HFNC flow, AH was influenced by $\mathbf{V}_{\mathrm{T}}$. At all experimental settings, AH remained $>30 \mathrm{mg} / \mathrm{L}$. Key words: high-flow nasal cannula; respiratory failure; oxygen therapy. [Respir Care 2014;59(8):1186-1190. (C) 2014 Daedalus Enterprises]
\end{abstract}

\section{Introduction}

Oxygen therapy is the first-line treatment for patients who suffer organ dysfunction, ${ }^{1-3}$ and nasal cannula is commonly used for low-flow oxygen delivery. This means of delivery is typically used for stable patients, for whom the $\mathrm{F}_{\mathrm{IO}_{2}}$ may vary

\footnotetext{
Dr Chikata is affiliated with the Medical Equipment Center, Tokushima University Hospital, and with the Department of Emergency and Critical Care Medicine, University of Tokushima Graduate School; Drs Izawa, Okuda, Itagaki, Nakataki, Onodera, and Nishimura are affiliated with the Department of Emergency and Critical Care Medicine, University of Tokushima Graduate School; and Dr Imanaka is affiliated with the Department of Emergency and Disaster Medicine, Tokushima University Hospital, Kuramoto, Tokushima, Japan.
}

according to breathing pattern. Oxygen flow is usually $1-6 \mathrm{~L} /$ min. Administration of $>6 \mathrm{~L} / \mathrm{min}$ does not greatly improve $\mathrm{F}_{\mathrm{IO}_{2}}$ and leads to nasal dryness, bleeding, and other discomfort to the patient. ${ }^{4} \mathrm{~A}$ simple oxygen mask is used to deliver higher flow of $5-12 \mathrm{~L} / \mathrm{min}$. When it does not meet patient demand, room air is drawn around the mask. $\mathrm{F}_{\mathrm{IO}_{2}}$ varies with

\footnotetext{
The authors have disclosed no conflicts of interest.

Correspondence: Masaji Nishimura MD, Department of Emergency and Critical Care Medicine, University of Tokushima Graduate School, 3-18-15 Kuramoto, Tokushima, Japan 770-8503. E-mail: nmasaji@ tokushima-u.ac.jp.
}

DOI: $10.4187 /$ respcare.02932 
mask fit, delivered flow, and patient minute volume. When flow is low, carbon dioxide is rebreathed.

In ICUs, high-flow nasal cannula (HFNC) therapy has become common for patients with unstable respiratory function. ${ }^{5} \mathrm{HFNC}$ can deliver up to $60 \mathrm{~L} / \mathrm{min}$ of heated and humidified medical gas, and $\mathrm{F}_{\mathrm{IO}_{2}}$ can be adjusted using a widebore nasal cannula. HFNC therapy is considered to create low levels of PEEP 6,7 and to reduce dead space. Effects on oxygenation, carbon dioxide $\left(\mathrm{CO}_{2}\right)$ elimination, and respiratory mechanics have been reported, ${ }^{8-11}$ No independent measurements on heat and humidity delivered during HFNC have been published. In the field of humidification, it is important to provide independent measurements of device performances, as discrepancies may exist between data provided by the manufacturers and bedside clinical data. ${ }^{12}$ We carried out this bench study to evaluate humidification performance of HFNC devices under various spontaneous breathing (SB) patterns and with different prong sizes.

\section{Methods}

We evaluated two types of HFNC (Airvo 2 and Optiflow systems, Fisher \& Paykel Healthcare, Auckland, New Zealand). In the Airvo 2, chamber-outlet temperature was set at $37^{\circ} \mathrm{C}$. The Optiflow system incorporated an $\mathrm{O}_{2}$ /air blender and a heated humidifier (MR850, Fisher \& Paykel Healthcare). The MR850 was set in invasive mode $\left(40^{\circ} \mathrm{C} /-3\right)$. For both systems, we tested HFNC flow of 20, 40, and $50 \mathrm{~L} / \mathrm{min}$. $\mathrm{F}_{\mathrm{IO}_{2}}$ was set at 0.21 for both devices. SB was simulated using a mechanical ventilator (Puritan-Bennett 840, Covidien, Carlsbad, California) and TTL test lung (TTL model 1601, Michigan Instruments, Grand Rapids, Michigan). To simulate SB, the muscle and lung compartment of the test lung were connected, after which the Puritan-Bennett 840 inflated the muscle compartment, and the lung compartment inspired medical gas delivered via HFNC and ambient air. One-way valves prevented mixing of inspired and expired gases. Compliance of the TTL test lung was $0.05 \mathrm{~L} / \mathrm{cm} \mathrm{H}_{2} \mathrm{O}$, and resistance was $5 \mathrm{~cm}$ of $\mathrm{H}_{2} \mathrm{O} / \mathrm{L} / \mathrm{s}$. We tested tidal volumes $\left(\mathrm{V}_{\mathrm{T}}\right)$ of 300,500 , and $700 \mathrm{~mL}$, and breathing frequencies of 10 and 20 breaths/ min. Inspiratory time was set at $1 \mathrm{~s}$ with square waveform, and it resulted in 18,30 , and $42 \mathrm{~L} / \mathrm{min}$ of SB inspiratory flow. Before experimental testing, a ventilator self-test was performed.

HFNC creates PEEP and increases residual volume in the lung compartment. We measured the end-expiratory pressure of the lung compartment and, to keep the residual volume of the muscle compartment at the same level as the lung compartment, set corresponding levels of PEEP on the PuritanBennett 840. To confirm $\mathrm{V}_{\mathrm{T}}$ delivered to the lung compartment, flow to the lung compartment was measured using a pneumotachometer $(4700$ series, $0-160 \mathrm{~L} / \mathrm{min}$, Hans Rudolph, Inc, Shawnee, Kansas) with a differential pressure transducer (TP-602T, $\pm 5 \mathrm{~cm} \mathrm{H}_{2} \mathrm{O}$, Nihon Kohden, Tokyo, Japan).

\section{QUICK LOOK}

\section{Current knowledge}

Heated and humidified high-flow oxygen via nasal cannula improves oxygenation by meeting patient inspiratory flow demand and providing a small positive airway pressures. Minute ventilation requirements are also reduced by washout of the upper airway anatomic dead space. Optimal heat and humidity levels are not known.

\section{What this paper contributes to our knowledge}

A bench study of two heated and humidified, high-flow nasal cannula systems demonstrated that an absolute humidity of $>30 \mathrm{mg}$ of $\mathrm{H}_{2} \mathrm{O} / \mathrm{L}$ was provided with both systems between 20 and $50 \mathrm{~L} / \mathrm{min}$. Absolute humidity decreased as tidal volume increased from 300 to $700 \mathrm{~mL}$.

We made two holes in a polyvinyl chloride cylinder to simulate external nares (Fig. 1). Into these holes, we inserted and tested small, medium, and large nasal prongs: OPT842, OPT844, and OPT846 with the Airvo 2; and OPT542, OPT544, and OPT546 with the Optiflow. The nasal prongs were connected to the manufacturer's standard circuit (900PT501 for the Airvo 2 and RT202 for the Optiflow). The external nares were connected to the TTL test lung via a standard ventilator circuit (Smoothbore tube 5000000, Intersurgical, Berkshire, United Kingdom). To prevent condensation, the circuit was placed in an incubator (V-2100G, No. 8090508, Atom Medical, Tokyo, Japan) in which the temperature was maintained at $37^{\circ} \mathrm{C}$. All experiments were performed in an air-conditioned room. See Figure 2 for experimental setup.

After each experimental setting was changed, we allowed at least $30 \mathrm{~min}$ for stabilization. Temperature, relative humidity, and absolute humidity (AH) of inspired gas downstream of the external nares were measured using a moisture sensor (Moiscope, Senko Medical, Tokyo, Japan; capacitance type, response time $3 \mathrm{~s}$ in the range $40-100 \%$ ). The hygrometer was calibrated at two points by using a cooler/heater water source (HHC-51, Senko Medical). Because condensation on sensor surfaces compromises the accuracy of humidity measurement, the sensor was withdrawn from the circuit during stabilization periods; after insertion for measurement, we monitored temperature, relative humidity, and $\mathrm{AH}$ for $10 \mathrm{~min}$, and after confirming the constancy of the values, we recorded temperature, relative humidity, and $\mathrm{AH}$ for the final $5 \mathrm{~min}$. All signals were processed through an analog/digital converter and saved on a computer at $50 \mathrm{~Hz} /$ channel using data acquisition software (WinDaq, Dataq Instruments, Akron, Ohio). For each experimental setting, we measured temper- 


\section{Humidification Performance of Two HFNCs}
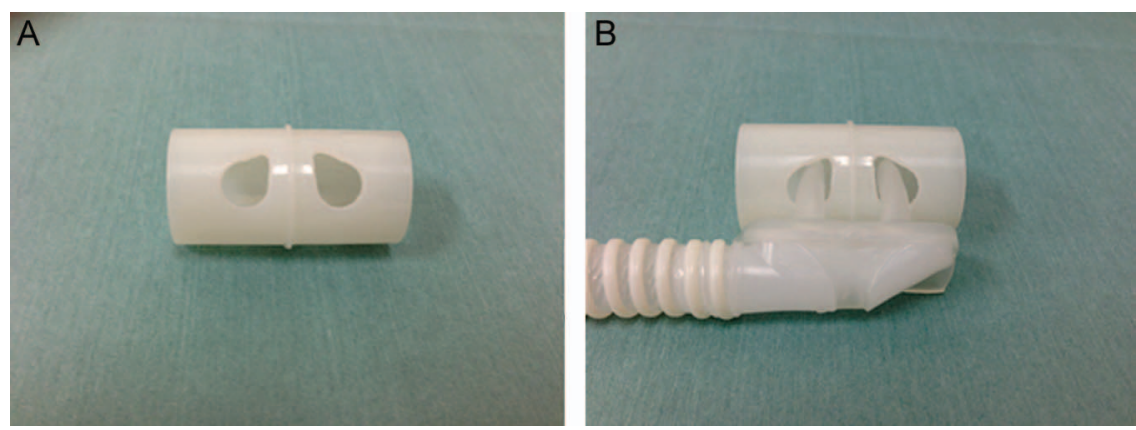

Fig. 1. Photographs of external nares. A: to simulate external nares, two holes were opened in a polyvinyl chloride cylinder. B: medium prongs attached to high-flow nasal cannula inserted into the simulated external nares. During the experiment, prongs were secured on the nares using tape.

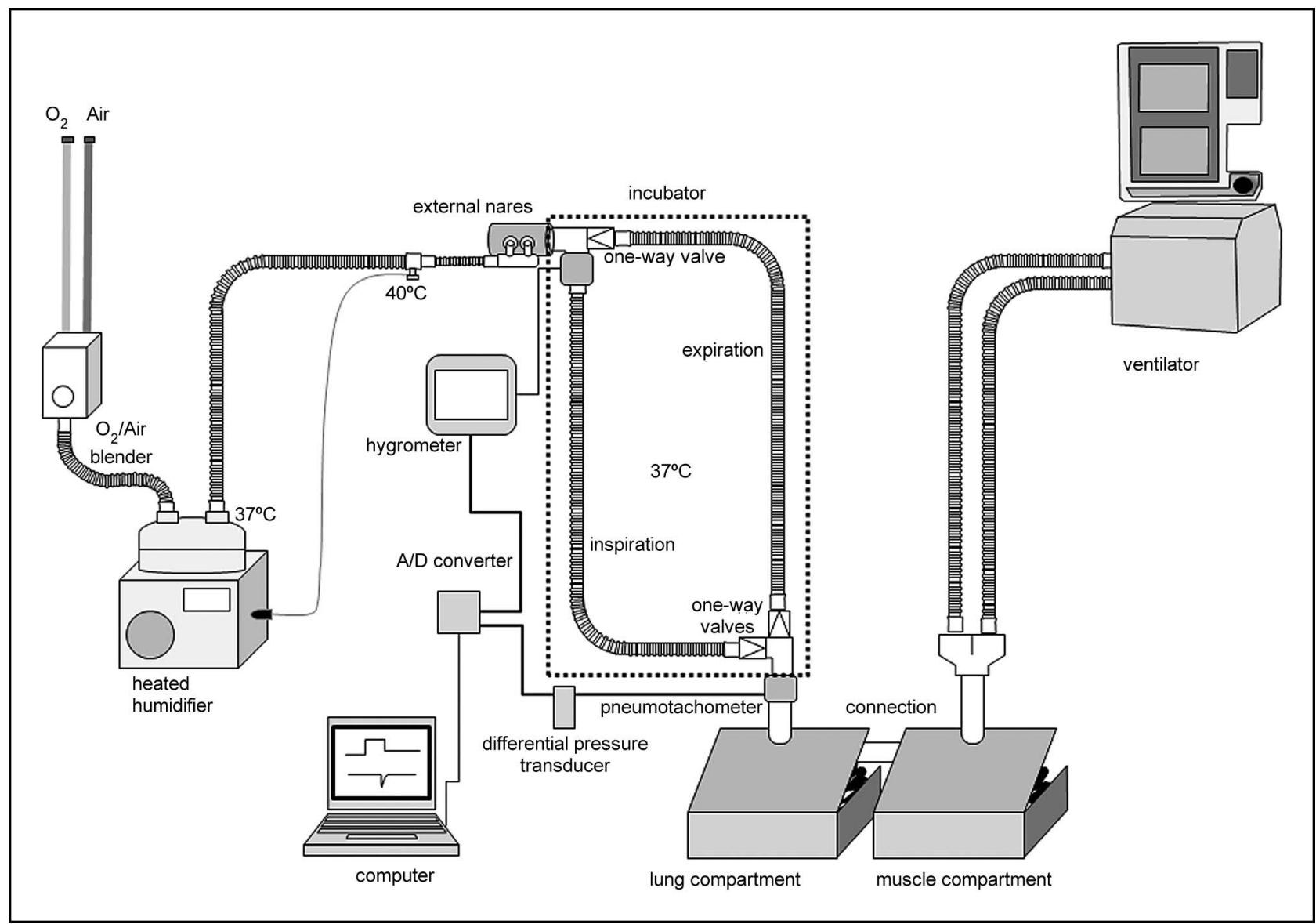

Fig. 2. A ventilator and TTL test lung were used to simulate spontaneous breathing. When a ventilator sends gas to the muscle compartment, the lung compartment attached to it starts inspiration. During simulated inspiration, ambient air is drawn into the lung compartment through the hygrometer. When the expiratory phase starts, gas in the lung compartment is expired to ambient space. We modeled external nares, which were connected to the simulated trachea. Each high-flow nasal cannula was connected to the simulated external nares using the manufacturer's standard circuit. The Airvo 2 was set at $37^{\circ} \mathrm{C}$, and the Optiflow was set to $40^{\circ} \mathrm{C}$ at the distal end of the breathing circuit and $37^{\circ} \mathrm{C}$ at the chamber outlet. The simulated trachea was placed in an incubator. To prevent condensation, the internal temperature of the incubator was maintained at $37^{\circ} \mathrm{C}$. One-way valves were connected on the limb of the simulated trachea to separate inspiratory and expiratory gases.

ature and $\mathrm{AH}$ for 5 breaths. The results were expressed as mean $\pm \mathrm{SD}$.
Analysis of variance was performed using repeated measures analysis of variance. All statistical tests were two- 

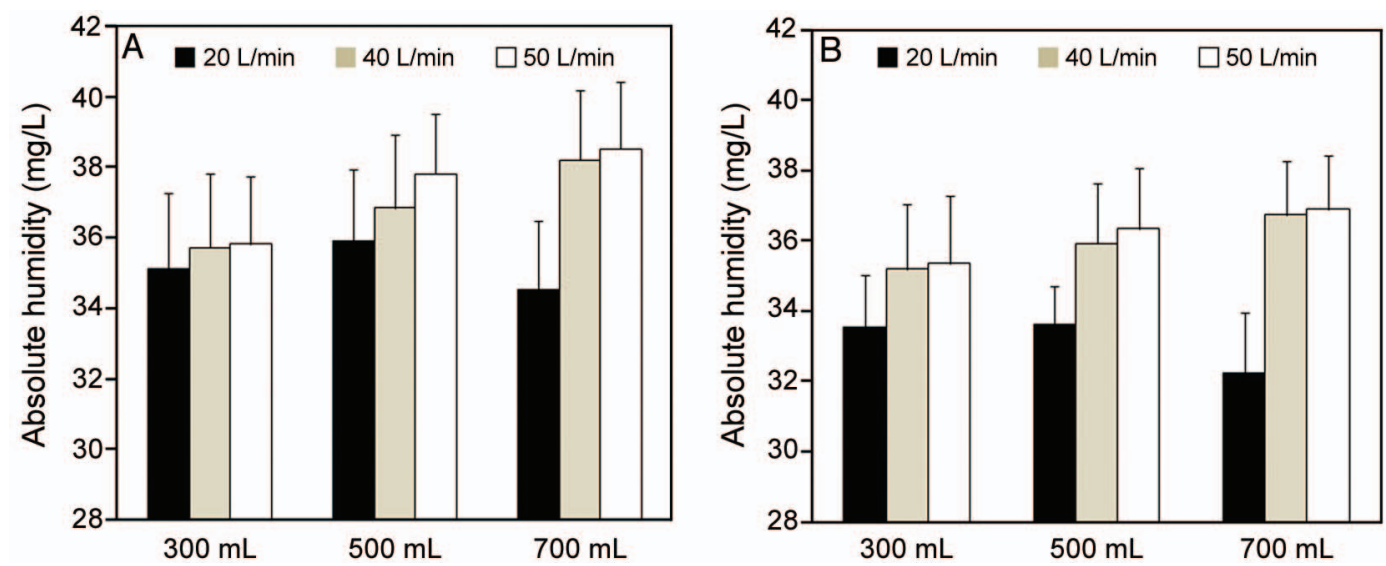

Fig. 3. Effects of flow and tidal volume $\left(\mathrm{V}_{\mathrm{T}}\right)$ on absolute humidity $(\mathrm{AH})$. At high-flow nasal cannula (HFNC) flow of $20 \mathrm{~L} / \mathrm{min}$, when $\mathrm{V}_{\mathrm{T}}$ increased from 300 to $700 \mathrm{~mL}, \mathrm{AH}$ decreased; at HFNC flow of 40 and $50 \mathrm{~L} / \mathrm{min}, \mathrm{AH}$ did not vary according to $\mathrm{V}_{\mathrm{T}}$. A: Airvo 2 HFNC. B: OptiFlow HFNC.

sided, and $P<.01$ was considered statistically significant. All statistical analysis was performed using commercial software (SPSS 11.01, SPSS, Chicago, Illinois).

\section{Results}

AH was $36.5 \pm 2.3 \mathrm{mg} / \mathrm{L}$ with the Airvo 2 , and $35.1 \pm$ $2.2 \mathrm{mg} / \mathrm{L}$ with the Optiflow system $(P<.01)$ at 20,40 , and $50 \mathrm{~L} / \mathrm{min}$, respectively; AH with the Airvo 2 was 35.2 $\pm 2.6,36.9 \pm 2.2$, and $37.4 \pm 2.1 \mathrm{mg} / \mathrm{L}$; and with the Optiflow, it was $33.1 \pm 1.5,35.9 \pm 1.7$, and $36.2 \pm 1.7$ $\mathrm{mg} / \mathrm{L}$ (Fig. 3). With both systems, AH was significantly higher at 40 and $50 \mathrm{~L} / \mathrm{min}$ than at $20 \mathrm{~L} / \mathrm{min}(P<.01)$. AH remained the same at 40 and $50 \mathrm{~L} / \mathrm{min}$.

At 300,500 , and $700 \mathrm{~mL}$ of $\mathrm{V}_{\mathrm{T}}$ respectively, $\mathrm{AH}$ with the Airvo 2 was $35.6 \pm 1.9,36.9 \pm 2.0$, and $37.1 \pm 2.6$ $\mathrm{mg} / \mathrm{L}$ and, with the Optiflow, $34.7 \pm 1.9,35.3 \pm 1.9$, and $35.3 \pm 2.7 \mathrm{mg} / \mathrm{L}$. While $\mathrm{V}_{\mathrm{T}}$ affected $\mathrm{AH}$ at $20 \mathrm{~L} / \mathrm{min}$ HFNC flow (Fig. 3), at 40 and $50 \mathrm{~L} / \mathrm{min}$ of HFNC flow, AH remained the same at 300,500 , and $700 \mathrm{~mL}$ of $\mathrm{V}_{\mathrm{T}}$. As breathing frequencies increased, AH increased $(P<.01)$. Prong size did not affect humidification for both devices.

Throughout the protocol, $\mathrm{AH}$ and the temperature of ambient air remained at $12.9 \pm 1.5 \mathrm{mg} / \mathrm{L}$ and $25.6 \pm 0.5^{\circ} \mathrm{C}$.

\section{Discussion}

In this first study to evaluate humidification performance under various SB patterns during $\mathrm{HFNC}$, we found $\mathrm{AH}$ was $>30 \mathrm{mg} / \mathrm{L}$ at all tested settings.

For face mask administration, Chanques et al ${ }^{13}$ previously reported median $\mathrm{AH}$ was 29.7 (24.4-30.6) mg/L; $\mathrm{AH}$ in the present study was higher. In their study, median flow was 7.8 (5.1-10.9) $\mathrm{L} / \mathrm{min}$, which was less than HFNC flow in the present study. In our experiment, we tested HFNC flow at 20, 40, and $50 \mathrm{~L} / \mathrm{min}$. Assuming that all delivered gas is inspired, humidity would depend on the inspiratory flow of SB and HFNC flow. When inspiratory flow is less than HFNC flow, patients would inspire only the gas delivered via HFNC, and humidification would depend almost entirely on the humidity of delivered gas. If inspiratory flow is greater than HFNC flow, patients would inspire both delivered gas and room air. SB inspiratory flow, respectively, was 18,30 , and $42 \mathrm{~L} / \mathrm{min}$ at $\mathrm{V}_{\mathrm{T}}$ of 300,500 , and $700 \mathrm{~mL}$. Consequently, when HFNC flow is $20 \mathrm{~L} / \mathrm{min}$, inspiratory flow would be greater than HFNC flow at $\mathrm{V}_{\mathrm{T}} 500$ and $700 \mathrm{~mL}$. We did, in fact, find with $20 \mathrm{~L} / \mathrm{min}$ of HFNC flow that AH was lower at 500 and $700 \mathrm{~mL}$ of $\mathrm{V}_{\mathrm{T}}$ than at $300 \mathrm{~mL}$ of $\mathrm{V}_{\mathrm{T}}$. Meanwhile, with 40 and $50 \mathrm{~L} / \mathrm{min}$ of HFNC, humidification did not differ according to $\mathrm{V}_{\mathrm{T}}$, because the flow was similar to or greater than SB inspiratory flow. Chikata et al, ${ }^{14}$ simulating highflow oxygen for tracheostomized patients in a bench study, reported findings similar to the present study; AH decreases as $\mathrm{V}_{\mathrm{T}}$ increases.

It is also necessary to ensure adequate humidification of the gas delivered via HFNC. Chanques et al ${ }^{13}$ compared bubble and heated humidifiers. With a heated humidifier, $\mathrm{AH}$ was 2 times higher than with a bubble humidifier. That study also used an MR850, which comprises a humidification chamber and a heated-wire circuit with $22 \mathrm{~mm}$ diameter tubing; the heated wire was set to maintain proximal temperature at $34^{\circ} \mathrm{C}$ and chamber temperature at $31^{\circ} \mathrm{C}$. Using the same heated humidifier for the Optiflow, our proximal temperature setting was $40^{\circ} \mathrm{C}$ and chamber setting was $37^{\circ} \mathrm{C}$. These setting differences enabled higher inspiratory $\mathrm{AH}$ in the present study. For the Airvo 2, we set only the chamber temperature, which was $37^{\circ} \mathrm{C}$. The Airvo 2 servo-controls the proximal temperature at approximately $40^{\circ} \mathrm{C}$. In this way we obtained similar, higher than previously reported, $\mathrm{AH}$ values with the Airvo 2 and with the Optiflow. 


\section{Humidification Performance of Two HFNCs}

AH was higher with the Airvo 2 than with the Optiflow. As described above, temperature control mechanisms differs between the devices, and it may cause higher $\mathrm{AH}$ with the Airvo 2. In addition, Airvo 2 measures ambient temperature because it uses ambient air, while the manufacturer does not provide an algorithm to control gas temperature by measuring ambient temperature. Another possibility was volume of the water chamber. Airvo 2 contains a larger volume of water, and this means more heat quantity.

Aside from being a bench study, our experiment was limited in other ways. For example, we tested only two HFNC devices, both from the same manufacturer, because they are the only ones currently available in Japan. We chose 20, 40, and $50 \mathrm{~L} / \mathrm{min}$ of HFNC flow because they are in the range commonly selected when using these devices. Oto et al have reported on humidification and mouth dryness during noninvasive ventilation. ${ }^{15}$ Measuring $\mathrm{AH}$ inside face masks during noninvasive ventilation, they found $\mathrm{AH}$ varied in the range from 23.1 to $33.3 \mathrm{mg}$ of $\mathrm{H}_{2} \mathrm{O} / \mathrm{L}$. If patients breathe through the mouth, they inspire more ambient air. Moreover, the $\mathrm{V}_{\mathrm{T}}$ of human beings varies, ${ }^{16}$ and $\mathrm{AH}$ might even vary breathby-breath in clinical patients. In HFNC therapy, flow is delivered at a constant rate, and $\mathrm{AH}$ of delivered gas might be more stable than with noninvasive ventilation.

We cannot assume, however, that HFNC always provides more stable humidification; results from our bench test cannot be directly applied to clinical settings. We firmly fixed the nasal prongs into the simulated external nares. In real life, the prongs usually move frequently. The present study was done only at $\mathrm{F}_{\mathrm{IO}_{2}}=0.21$. Optiflow uses only medical gases, air and oxygen are mixed upstream of the water chamber, and $\mathrm{AH}$ is not influenced by $\mathrm{F}_{\mathrm{IO}_{2}}$. In contrast, Airvo 2 uses ambient air, and dry oxygen is added upstream of the water chamber. Under high $\mathrm{F}_{\mathrm{IO}_{2}}$, AH could decrease. We set the invasive mode of MR850 with the Optiflow. Vapor output is different between the invasive and noninvasive modes, and $\mathrm{AH}$ must be lower in noninvasive mode.

\section{Conclusions}

We bench-tested inspiratory gas humidification during HFNC therapies with a simulated SB. At all experimental settings, AH was $>30 \mathrm{mg} / \mathrm{L}$. During bench use of HFNC, $\mathrm{AH}$ increased with increasing HFNC flow. Although SB inspiratory flow exceeded HFNC flow, AH was influenced by $\mathrm{V}_{\mathrm{T}}$; humidification is sufficient for patients with $\mathrm{SB}$ at
$20-50 \mathrm{~L} / \mathrm{min}$ of HFNC flow with the devices investigated in the present study.

\section{REFERENCES}

1. Kallstrom TJ, American Association for Respiratory Care. AARC Clinical Practice Guideline: oxygen therapy for adults in the acute care facility: 2002 revision \& update. Respir Care 2002;47(6):717720.

2. Mithoefer JC, Karetzky MS, Mead GD. Oxygen therapy in respiratory failure. N Engl J Med 1967;277(18):947-949.

3. Maroko PR, Radvany P, Braunwald E, Hale SL. Reduction of infarct size by oxygen inhalation following acute coronary occlusion. Circulation 1975;52(3):360-368.

4. Campbell EJ, Baker MD, Crites-Silver P. Subjective effects of humidification of oxygen for delivery by nasal cannula: a prospective study. Chest 1988;93(2):289-293.

5. Ricard JD. High flow nasal oxygen in acute respiratory failure. Minerva Anestesiol 2012;78(7):836-841.

6. Parke R, McGuinness S, Eccleston M. Nasal high-flow therapy delivers low level positive airway pressure. BJA 2009;103(6):886-890.

7. Groves N, Tobin A. High flow nasal oxygen generates positive airway pressure in adult volunteers. Aust Crit Care 20(4)07;20:126131.

8. Itagaki T, Okuda N, Tsunano Y, Kohata H, Nakataki E, Onodera M, et al. Effect of high-flow nasal cannula on thoraco-abdominal synchrony in adult critically ill patients. Respir Care 2014;59(1):70-74.

9. Lenglet H, Sztrymf B, Leroy C, Brun P, Dreyfuss D, Ricard JD. Humidified high flow nasal oxygen during respiratory failure in the emergency department: feasibility and efficacy. Respir Care 2012; 57(11):1873-1878.

10. Sztrymf B, Messika J, Mayot T, Lenglet H, Dreyfuss D, Ricard JD. Impact of high-flow nasal cannula oxygen therapy on intensive care unit patients with acute respiratory failure: a prospective observational study. J Crit Care. 2012;27(3):324,e9-e13.

11. Sztrymf B, Messika J, Bertrand F, Hurel D, Leon R, Dreyfuss D, Ricard JD. Beneficial effects of humidified high flow nasal oxygen in critical care patients: a prospective pilot study. Intensive Care Med 2011;37(11):1780-1786.

12. Thiéry G, Boyer A, Pigné E, Salah A, De Lassence A, Dreyfuss D, Ricard JD. Heat and moisture exchangers in mechanically ventilated intensive care unit patients: a plea for an independent assessment of their performance. Crit Care Med 2003;31(3):699-704.

13. Chanques G, Constantin JM, Sauter M, Jung B, Sebbane M, Verzilli $\mathrm{D}$, et al. Discomfort associated with under humidified high-flow oxygen therapy in critically ill patients. Intensive Care Med 2009; 35(6):996-1003.

14. Chikata Y, Oto J, Onodera M, Nishimura M. Humidification performance of humidifying devices for tracheostomized patients with spontaneous breathing: a bench study. Respir Care 2013;58(9):1442-1448.

15. Oto J, Nakataki E, Okuda N, Onodera M, Imanaka H, Nishimura M. Hygrometric properties of inspired gas and oral dryness in patients with acute respiratory failure during noninvasive ventilation. Respir Care 2014;59(1):39-45.

16. Askanazi J, Silverberg PA, Hyman AI, Rosenbaum SH, Foster R, Kinney JM. Patterns of ventilation in postoperative and acutely ill patients. Crit Care Med 197(2)9;7:41-46.

This article is approved for Continuing Respiratory Care Education credit. For information and to obtain your CRCE

(free to AARC members) visit www.rcjournal.com

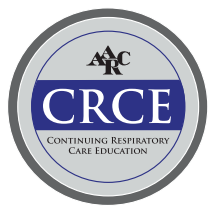

